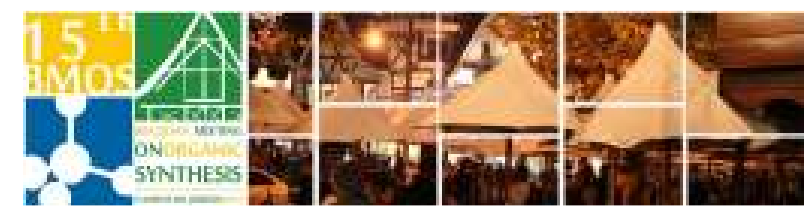

\title{
Bromination of 4-bromoindanone and 5-bromoindanone
}

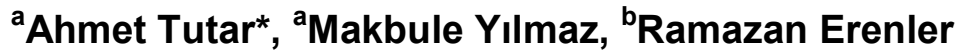 \\ ${ }^{a}$ Sakarya University, Faculty of Art and Science, Department of Chemistry, TR-54187 Adapazari, Turkey \\ ${ }^{b}$ Gaziosmanpasa University, Faculty of Art and Science, Department of Chemistry, TR-60240 Tokat, Turkey \\ *e-mail corresponding author:atutar@sakarya.edu.tr
}

Keywords: Bromination reactions, bromoindanone.

\section{INTRODUCTION}

Brominations of hydrocarbons are important processes in synthetic chemistry. ${ }^{1-2}$ Brominated compounds are valuable starting materials for organometallic reagents ${ }^{3}$ and coupling reactions. ${ }^{4}$ Indanes and indanones are used extensively in medicinal chemistry. ${ }^{5}$

Herein, we carried out the bromination reactions of 4-bromoindanone, 5-bromoindanone and formed the di- and tribromoindanone which could be the precursors for synthesis pharmaceutically, synthetically and medicinally important compounds.

\section{RESULTS AND DISCUSSION}

The treatment of 4-bromoindanone (1) with 2.2 equivalent of bromine at room temperature for $2 \mathrm{~h}$ yielded 2,2,4-tribromoindanone (2) in quantitative amount. 4-bromoindanone (1) reacted with bromine in carbon tetrachloride and triethylamine while irradiation with a $150 \mathrm{~W}$ projector lamp for $12 \mathrm{~h}$ gave dibromide 3 (65\%). 2,2,5-tribromoindanone (5) was generated by treatment of 5-bromoindanone (4) with 2.2 equivalent of bromine in dichloromethane at $\mathrm{rt}$ for $2 \mathrm{~h}$ in a yield of $90 \%$. The reaction of 5 bromoindanone with 3.2 equivalent of bromine in carbontetrachloride and $\mathrm{Et}_{3} \mathrm{~N}$ at rt while irradiation with a $150 \mathrm{~W}$ projector lamp for $12 \mathrm{~h}$ gave 2,3,5tribromoindenone (6) in $58 \%$ yield. (Scheme).

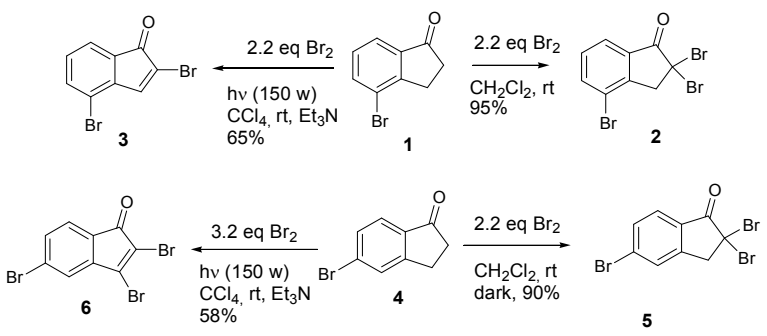

Scheme: Bromination reactions of 4-bromoindanone and 5-bromoindanone
Table 1. ${ }^{1} \mathrm{H}-\mathrm{NMR}\left(300 \mathrm{MHz}, \mathrm{CDCl}_{3}\right),{ }^{13} \mathrm{C}-\mathrm{NMR}$ values of synthesized compounds, 2,3,5,6.

\begin{tabular}{|c|c|}
\hline Comp. & Spectral Values \\
\hline 2 & $\begin{array}{l}{ }^{1} \mathrm{H}-\mathrm{NMR}: 7.92-7.86(\mathrm{~m}, 2 \mathrm{H}), 7.44-7.38 \\
(\mathrm{~m}, 1 \mathrm{H}), 4.20\left(\mathrm{~s}, \mathrm{CH}_{2}\right) .{ }^{13} \mathrm{C}-\mathrm{NMR}: 192.4, \\
147.2,139.8, \quad 131.4,130.9,125.6 \text {, } \\
121.4,55.6,53.3\end{array}$ \\
\hline 3 & $\begin{array}{l}{ }^{7} \mathrm{H}-N M R: 7.8(\mathrm{~s}, 1 \mathrm{H}), 7.35-7,45(\mathrm{~m}, 2 \mathrm{H}) \text {, } \\
7.05-7.12(\mathrm{~m}, 1 \mathrm{H})\end{array}$ \\
\hline 5 & $\begin{array}{l}{ }^{1} \mathrm{H}-\mathrm{NMR}: 7.82-7.78(\mathrm{~d}, 1 \mathrm{H}), 7.66-7.58 \\
(\mathrm{dd}, 2 \mathrm{H}), 4.20 \quad\left(\mathrm{~S}, \mathrm{CH}_{2}\right) .{ }^{13} \mathrm{C}-\mathrm{NMR}: \\
191.9, \quad 148.8, \quad 133.0, \quad 132.7, \quad 129.5 \text {, } \\
\begin{array}{l}128.1,128,0,56,0,52,1\end{array}\end{array}$ \\
\hline 6 & $\begin{array}{l}{ }^{1} \mathrm{H}-\mathrm{NMR}: 7.50-7.46 \quad(\mathrm{~m}, 1 \mathrm{H}), \quad 7.34-7.26 \\
(\mathrm{~m}, 2 \mathrm{H}),{ }^{13} \mathrm{C}-\mathrm{NMR}: 185.6,144.8,144.3 \text {, } \\
\text { 132.8, 129.6, 127.7, } 124.9,124.3,124.0\end{array}$ \\
\hline
\end{tabular}

\section{CONCLUSION}

Bromination of 4-bromoindanone (1) and 5bromoindanone (4) were accomplished efficiently and optimum reaction conditions were presented.

\section{ACKNOWLEDGEMENTS}

The authors thank to the Sakarya University Research Foundation (BAP-2010-02.04.06).

\section{REFERENCES}

${ }^{1}$ Cakmak, O.; Erenler, R.; Tutar, A.; Celik, N. J.Org. Chem. 2006, 71, 1795. ${ }^{2}$ Tutar, A.; Balci, M. Tetrahedron, 2002, 58, 8979.

${ }^{3}$ Anderson, H. L.; Walter, C. J.; Vidal-Ferran, A.; Hay, R. A.; Lowden, P. A.; Sanders, J. K. M. J. Chem. Soc., Perkin Trans. 1 1995, 18, 2275.

${ }^{4}$ Miyaura, N.; Suzuki, A. Chem. Rev. 1995, 95, 2457.

${ }^{5} \mathrm{Hu}, \mathrm{H}$.; Hollinshead, S. P.; Hall, S. E.; Kalter, K.; Ballas, L. M. Bioorg. Med. Chem. Lett. 1996, 6, 973-978. 